\title{
Effect of Topology on Hybrid-linked Jet Impingement
}

Li Yang, Sarwesh Narayan Parbat, Zheng Min, Minking K Chyu 


\title{
Effect of Topology on Hybrid-linked Jet Impingement
}

\begin{abstract}
Present paper considers hybrid-linked jet impingement which involves both parallel linked jets and serial linked jets. Eight configurations with different topologies were tested under five mass flow rates ranging from 0.4 to $0.8 \mathrm{~kg} / \mathrm{m}^{2} \mathrm{~s}$. The equivalent Reynolds numbers range from 12,000 to 24,000 for serial linked jets. Both heat transfer data and pressure drop data were obtained from the steady state experiments. Due to the parallel linkage, the heat transfer for the parallel jets decreases with increasing total number of parallel jets, while the heat transfer for the serial jets stay constant regardless of the change in topology. Although the serial jets are inclined, the heat transfer level of serial jets are typically higher than parallel jets due to the concentration of mass flow rate. Case 1 with purely serial linked jets shows a heat transfer enhancement by $100 \sim 150 \%$ as compared to the traditional design Case 8 . However, the pressure drop of such configuration is around 20 times higher than that of the traditional designs. Analytical modelling work shows that the overall averaged heat transfer is a weighted average of $[(m / A) / n]^{0.4}$ and $(m / A)^{0.4}$, which represents the heat transfer induced by parallel jets and serial jets respectively.
\end{abstract}

Keywords: Heat Transfer, Jet Impingement, Topology 


\section{Nomenclature}

$A \quad$ area of the target surface, $\mathrm{m}^{2}$

$D_{\mathrm{j}} \quad$ impingement hole diameter, $\mathrm{mm}$

$h \quad$ heat transfer coefficient, $\mathrm{W} / \mathrm{m}^{2} \mathrm{~K}$

$k \quad$ thermal conductivity, $\mathrm{W} / \mathrm{mK}$

$L \quad$ thickness of the horizontal jet plate, $\mathrm{mm}$

$m \quad$ mass flow rate, $\mathrm{kg} / \mathrm{s}$

$m / A$ mass flow rate per cooled area, $\mathrm{kg} / \mathrm{m}^{2} \mathrm{~s}$

$n \quad$ number of parallel jets in the horizontal plate

$\mathrm{Nu} \quad$ Nusselt number

$N u_{\text {ave }} \quad$ overall area averaged Nusselt number

$P_{\mathrm{x}} \quad$ jet hole pitch in streamwise direction, $\mathrm{mm}$

$P_{\mathrm{y}} \quad$ jet hole pitch in spanwise direction, $\mathrm{mm}$

$P_{\mathrm{z}} \quad$ distance from jet exit to target wall, $\mathrm{mm}$

$p \quad$ pressure, $\mathrm{Pa}$

$p_{\mathrm{t}, \mathrm{i}} \quad$ inlet total pressure, $\mathrm{Pa}$

$p_{\mathrm{o}} \quad$ outlet static pressure, $\mathrm{Pa}$

$p^{*} \quad$ non-dimensional pressure drop

$q$ " heat flux, $\mathrm{W} / \mathrm{m}^{2}$

Re Reynolds number

$t \quad$ thickness of the vertical jet plate, $\mathrm{mm}$

$T$ temperature, $\mathrm{K}$

$T_{\text {bulk }} \quad$ temperature of the bulk flow, $\mathrm{K}$

$T_{\mathrm{w}} \quad$ wall temperature, $\mathrm{K}$ 
$w_{\mathrm{o}} \quad$ outlet slot width, mm

$X \quad$ length of target surface, $\mathrm{mm}$

Greek symbols

$\rho \quad$ density, $\mathrm{kg} / \mathrm{m}^{3}$

$\mu \quad$ dynamic viscosity, $\mathrm{Pa} \cdot \mathrm{s}$ 


\section{Introduction}

Jet impingement cooling is widely used in industrial applications such as gas turbine airfoil cooling, electronic chip cooling and vehicle heat exchangers. The intensive and localised heat transfer provided by jet impingement makes it suitable for thermal related problems with various conditions and geometries. While impinging jets can significantly enhance heat transfer, the pressure drop spent to eject the coolant through the jet plates is also rather high. Designers who use jet impingement always seek for the balance between heat transfer and driving power, which leads to numerous research work on jet impingement.

Early studies of jet impingement in the last century are summarized by Han and Goldstein [1] and Viskanta et al. [2]. Research work prior to 2001 has involved numerous studies on single jet, single array jets and multiple array jets. Correlations derived from these studies provided great aid to both heat transfer and pressure prediction. An excellent and quite popular piece of work among these is the Florschuetz's correlation [3], which includes a wide range of flow parameters and the local effect of cross flow. Recent investigations prior to 2005 can be found in Zukerman and Lior's [4] review paper. Experimental data including stagnation point and spatiallyaveraged surface heat transfer coefficients were summarized with a jet Reynolds number ranging from 1,500 to 400,000 . Also included in this summary is the comparison between turbulence models used to predict impingement heat transfer. The shear stress Transport model, as recommended by their work, is the most suitable two equation turbulence model for impingement flow. In gas turbine areas, a comprehensive review of airfoil cooling structures prior to 2012 can be found in the book by Han et al.

[5]. Based on their summary, impingement is one of the most effective cooling 
technology for gas turbines components, which include airfoils, combustor liners and passage platforms.

Recent studies of jet impingement considered new factors that influence or enhance impingement heat transfer, such as bulk temperature, surface features, curvatures and rotation. Experimental work by Ricklick et al. [6-8] investigated the influence of channel height, jet space and bulk temperature on single inline row of impinging jets. The choice of bulk temperature is important to determine the heat transfer coefficient and avoid a large uncertainty caused by inaccurate bulk temperature. Impingement cooling on rib-roughed leading edge surface was investigated by Taslim et al. [9-11]. Notched-horseshoe ribs produced the highest heat removal from the target surface, which was attributed entirely to the area increase of the target surface. Parsons et al. [12] focused on the effect of rotation on a radially outward channel with a single array of impinging jets on both the leading and trailing sides. The jet Reynolds number was 10,000 and the rotation number was 0.0028 . Heat transfer on all sides of the channel decreased up to 20 percent compared to those results that correspond to nonrotating conditions. Detailed measurement of the flow field and Nusselt number distribution have been carried out by Kreatsoulas et al. [13, 14] with aid of infrared cameras. A decrease in the averaged Nusselt number by up to 30 percent was observed at high rotation speeds. A series of correlations for Nusselt number were derived with a formula consisting of rotation number, Reynolds number and Rayleigh number. Investigations combining the effect of target surface conditions and rotation can be found in Elston and Wright [15, 16], Hong et al [17-19]. and Lamont et al. [20-22]. Measurement technologies used by these research teams include transient liquid crystal, Infrared imaging, particle image velocimetry, and Naphthalene sublimation. Most recent 


\section{Effect of Topology on Hybrid-linked Jet Impingement}

study by Li et al. [23, 24] focused on impingement with extremely low jet to target distance (less than one jet diameter). With systematic experimental analysis, the authors provided a correction formula of Florschuetz's correlation which fits well with experimental data both for low jet to target distance and regular parameter range.

Substantial effort was devoted to development of structures to reduce the cumulative impact caused by the cross flow. Haumann et al. [25] applied trapezoidal corrugated orifice on multiple jet impingement. Cross flow can be routed away from the trapezoid passage surrounded by the orifice wall, which decreases the pressure drop in the cooling channel. Correia [26] changed the design to a corrugated orifice with increasing height in the bulged part. Results indicated that the modified cooling configuration was suitable for reducing the defects from cross flow rate. Bunker and Wallace [27] used extended port for the impinging jets. Heat transfer can be enhanced largely due to the low nozzle to target distance while the pressure drop is kept low. Esposito et al. [28] investigated the effect of geometrical parameters on impingement with corrugated orifice. The average jet Reynolds number was varied from 20,000 to 60,000. Corrugated orifice geometries with smaller bypass channels outperformed the geometries tested with larger channels. The use of corrugated jet impingement configurations would allow larger jet impingement arrays without sacrificing heat transfer effectiveness. Chi et al. [29] tested impingement cooling with corrugated orifices in a much larger parameter range both experimentally and numerically. It was found that the novel impingement cooling structures provide lower flow resistance and more homogeneous heat transferring intensity on the target surface. The partial wall temperature of the first stage guide vanes can be reduced by $10 \mathrm{~K}$ to $30 \mathrm{~K}$ with the same 
pressure drop and mass flow rate of cooling air according to this 3-D numerical investigations.

Most impingement cooling configurations employ multiple arrays of jets, which enhance the heat transfer by pushing the flow through parallel orifices to hit the target surfaces. Jet flows in this kind of configurations are typically linked in parallel to each other, resulting in highly distributed coolant flow and low local jet Reynolds numbers. On the contrary, if jets are linked in series, local Reynolds numbers will increase multiple times and the heat transfer will be significantly enhanced. However, very few studies considered jets in series connection, except for some impingement structures used in airfoil trailing edges. One major reason is the difficulty of manufacturing serial linked jet plates. In recent years, development of new manufacturing technologies like multiple core casting and additive manufacturing has made it possible to make complex cooling structures with serial linked jets. Previous numerical study of Yang et al. [30] indicated that serial linked jets can significantly enhance the cooling efficiency, which has a potential to save coolant mass flow rate by $50 \%$ for turbine airfoils in the engine specific conditions.

Present paper considers hybrid-linked jet impingement which involves both parallel linked jets and serial linked jets. Eight configurations with different topologies were tested under five mass flow rates ranging from 0.4 to $0.8 \mathrm{~kg} / \mathrm{m}^{2} \mathrm{~s}$. The equivalent Reynolds number ranges from 12,000 to 24,000 for the serial linked case. Both heat transfer data and pressure drop data were obtained from the steady state experiments. Such effort is expected to introduce a new parameter to jet impingement design, which might result in a series of more flexible cooling concepts. 


\section{Methodologies and Setups}

\section{Topologies and geometries}

Present study focuses on air cooled channels with hybrid-linked jets. The proposed concept of hybrid linked jet impingement includes both parallel linked jets and serial linked jets. Figure 1 shows the spanwise cross section of the cooling concept. Working fluid enters the rectangular plenum, passes through a horizontal jet plate followed by several vertical jet plates, and eventually exits from the outlet slot. The socalled "parallel linked jets" refer to the jets located in the horizontal plate as flow directions in these jets are almost parallel. Similarly, jets on the vertical plates are named as "serial linked jets" in this paper due to their serial flow sequence. Cooling channels which contain both serial linked jets and parallel linked jets are then considered to have hybrid topologies, which is the key and unique feature of present study.

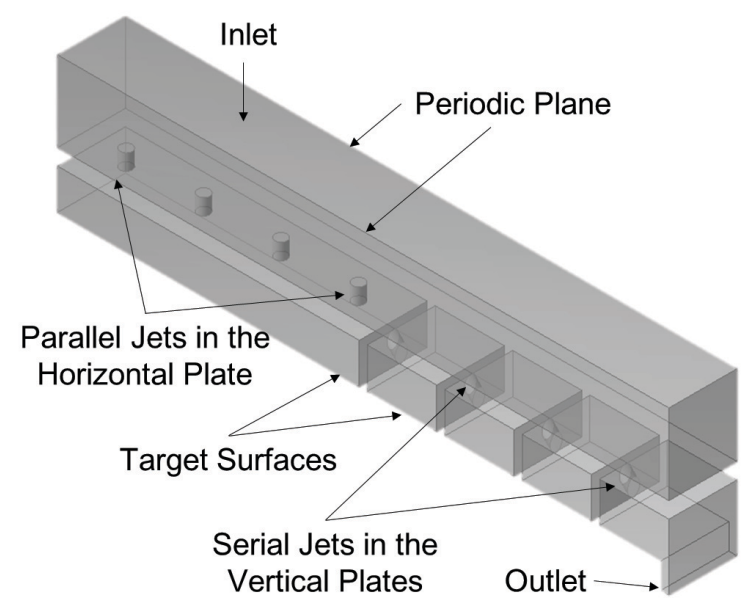

Figure 1 Concept of Hybrid Linked Jet Impingement Channel

Variables and parameters involved in present study include topology (linkage of jets) and mass flow rates. Heat transfer coefficients and pressure drops were evaluated 
for each combination of parameters to reveal the effect of topology on performance. The selected geometries in present study includes eight topologies, as shown in Figure 2. The case number $n$ is defined based on the number of jets in the horizontal plate, which also represents the topology of each case. For all cases, the parallel jets are all present in the horizontal plate upstream while all the remaining jets are located in the vertical plates downstream. It should be noted that there are still many intermediate topologies besides the selected ones, as parallel linked jets and serial linked jets can exchange locations with each other randomly. Those random topologies may cause inappropriate flow and pressure distribution with parallel linked jets in the far downstream region as described in the author's previous work [30]. Consequently, present study forces all serial linked jets to appear after all parallel linked jets to maintain proper flow patterns.

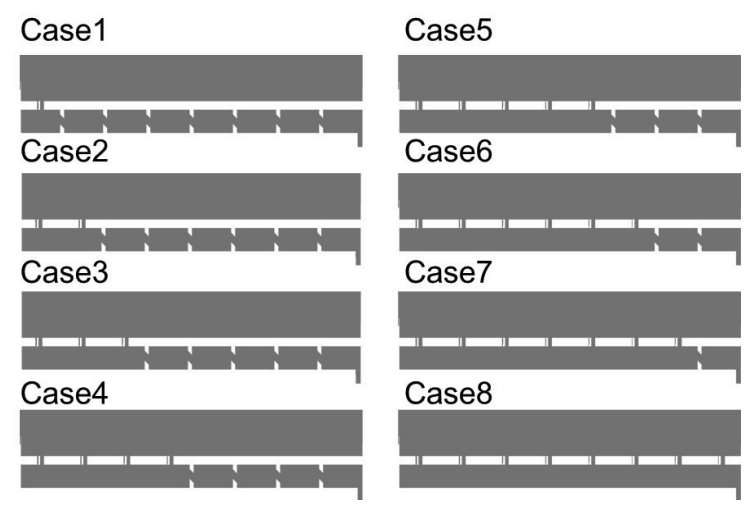

Figure 2 Definition of Topologies for Each Case

Other geometric parameters of present study, besides topology $(n)$, include several commonly used geometric variables for impingement as shown in Figure 3 and Table 1 . All jet diameters $D_{\mathrm{j}}$ are $1.5 \mathrm{~mm}$. The streamwise hole pitch over jet diameter $P_{\mathrm{x}} /$ $D_{\mathrm{j}}=6.35$. The spanwise hole pitch $P_{\mathrm{y}} / D_{\mathrm{j}}=5.64$. The jet to target distance $P_{\mathrm{z}} / D_{\mathrm{j}}=3.87$. The thickness of the horizontal plate $L / D_{\mathrm{j}}=1.33$, and the thickness of the vertical jet 
plates $t / D_{\mathrm{j}}=0.67$. The width of the outlet slot $w_{\mathrm{o}}=1 \mathrm{~mm}$. All jets in the vertical plate have a 45 degree angle with the plate normal direction. These parameters were kept constant as present study only focused on the effect topology. Also, this set of parameters are well within the traditional parameter range of impingement.

Table 1 Constant Geometry Parameters for Impingement

\begin{tabular}{ccccccccc}
\hline Parameter & $D_{\mathrm{j}}$ & $P_{\mathrm{x}} / D_{\mathrm{j}}$ & $P_{\mathrm{y}} / D_{\mathrm{j}}$ & $P_{\mathrm{z}} / D_{\mathrm{j}}$ & $L / D$ & $t / D$ & $w_{\mathrm{o}}$ & $\alpha$ \\
\hline Value & $1.5 \mathrm{~mm}$ & 6.35 & 5.64 & 3.87 & 1.33 & 0.67 & $1 \mathrm{~mm}$ & $45^{\circ}$ \\
\hline
\end{tabular}

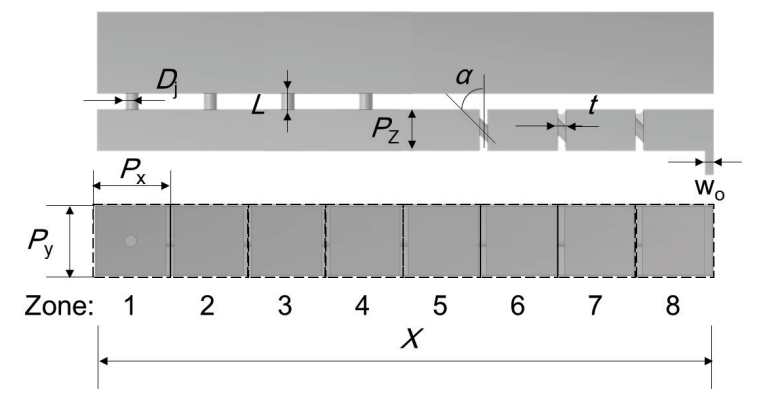

Figure 3 Definition of Geometric Parameters

All the eight configurations were evaluated under five mass flow rates. As the mass flow rates are maintained consistent among all cases, local Reynolds numbers varies from case to case. As a result, present study employs an area averaged mass flow rate $m / A$ to replace local Reynolds numbers, which represents the ratio of mass flow rate over target surface area. Such area averaged mass flow rate $m / A$ ranges from 0.4 to 0.8 $\mathrm{kg} / \mathrm{m}^{2} \mathrm{~s}$ in present study, consequently resulting in a series of Reynolds numbers ranging from 12,000 to 24,000 for Case 1, based on the jet diameter and jet velocity. Eq. 1 shows the definition of the Reynolds number.

$$
R e=4 m / \pi \mu D_{\mathrm{j}}
$$




\section{Effect of Topology on Hybrid-linked Jet Impingement}

\section{Experimental setup}

The heat transfer and pressure drop evaluation for the above cases was conducted in the gas turbine heat transfer laboratory at University of Pittsburgh. Averaged heat transfer coefficients were obtained with the aid of thin-foil heaters and thermocouples. Figure 4 shows the layout of the steady state test rig. A compressed air supply with pressure capability of $600 \mathrm{kPa}$ fed the entire system. During the tests, cooling air at room temperature was first regulated by a pressure regulator, passed through an OMEGA FLR6725D flowmeter and then introduced to the test section through a flexible pipe. A DC power supply with an ultrathin film heater provided the heating for the test section. Temperature and pressure information were monitored by several thermocouples and a pressure gauge, which then transferred the real time information to the data acquisition system.

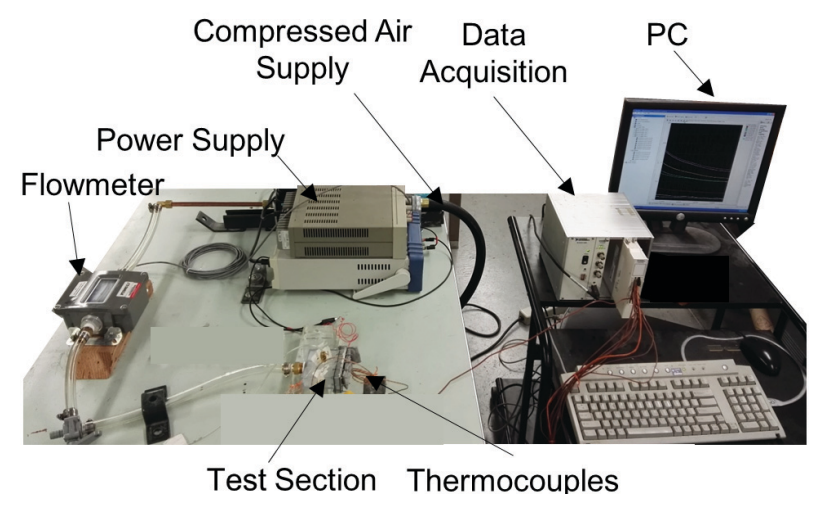

Figure 4 Steady State Heat Transfer Test Rig for Impingement Cooling

Details of the test section are described by Figure 5 and Figure 6 . The parts with complex jet plates were manufactured through Stereolithography 3-D printing. The top of the jet plate was connected to the feeding plenum made out of acrylic while aluminium bars were attached to the bottom. Here, each aluminium sheet served as the 
target surface of heat transfer in each zone as defined in Figure 3. These components, which form the flow passage, were designed with slightly tight fitting to minimize potential leakage. Beneath each aluminium sheet, there was one thermocouple installed in a carefully designed groove, which was then fixed onto the aluminium plates with a layer of conductive tape. An ultra-thin film heater was attached to the bottom surface of the aluminium plates to provide a constant heat flux of $0 \sim 15 \mathrm{~kW} / \mathrm{m}^{2}$, which maintained a wall temperature of $35 \sim 60{ }^{\circ} \mathrm{C}$ for the aluminium sheets. A cover plate tightened the entire test section with the aid of fasteners through the flanges and gaskets. This assembled test section was then sealed with silicon glue at all edges and covered with insulation foam on the outside. In addition to the thermocouples in solid parts, two more thermocouples were installed at the inlet and outlet to measure the bulk temperature. Also measured was the pressure at the inlet by the pressure gauge. The test section discussed above contained a fluid domain consisting of three rows of jets to approximately maintain periodic boundary conditions for the middle row. Heat transfer data were acquired only for the middle row of jets.

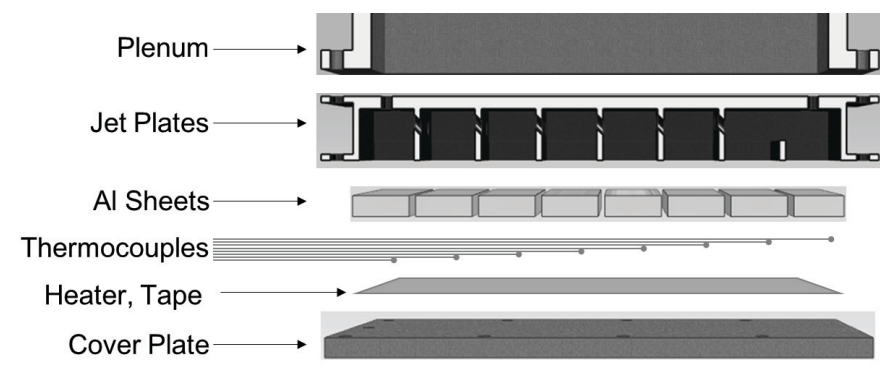

Figure 5 Cross Section View of Test Section Design 


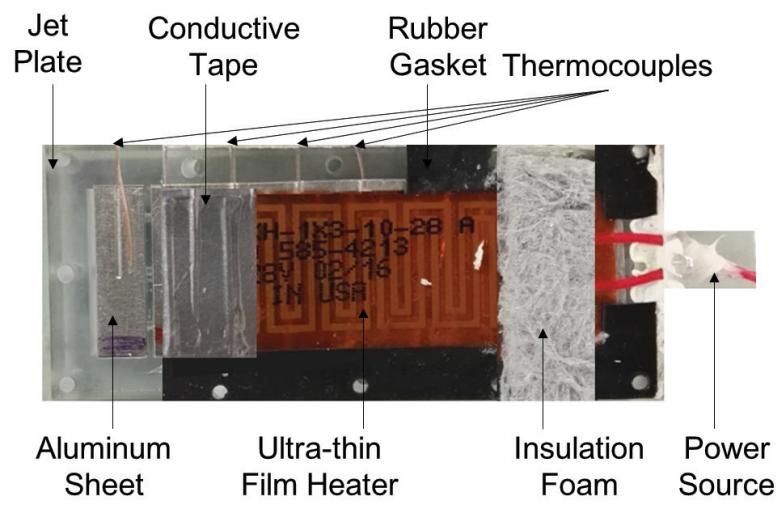

Figure 6 Top View of the Assembled Test Section

\section{Post process}

Present study defined two non-dimensional parameters to represent the performance of the cooling channels, which included a Nusselt number and a pressure drop. As both local temperatures and local flow velocities vary from case to case, the non-dimensional variables had to be defined based on constant dimensions to maintain consistency between different cases. The Nusselt number (see Eq. 2) was based on the jet diameter and the heat transfer coefficients (see Eq. 3) which had an associated local bulk temperature at the exit of corresponding jets. Such local bulk temperatures were estimated using a linear interpolation between the measured inlet and the outlet temperatures along the channel length $X$. Present study also normalized the measured pressure drop with the outlet pressure $p_{\mathrm{o}}$. Eq. 4 shows the definition of this pressure ratio.

$$
\begin{aligned}
& N u=h D_{\mathrm{j}} / k \\
& h=q " /\left(T_{\mathrm{w}}-T_{\text {bulk }}\right)
\end{aligned}
$$




$$
p^{*}=\left(p_{\mathrm{t}, \mathrm{i}}-p_{\mathrm{o}}\right) / p_{\mathrm{o}}
$$

The heat transfer coefficients mentioned above were calculated by a linear regression process instead of directly calculating the ratio of heat fluxes over temperature differences. The regression process took the changes of temperatures corresponding to the change of heat fluxes. Heat transfer data generated through regression process were considered to have higher accuracy than direct calculation because they depend less on the absolute values of thermocouples readings. Figure 7 shows an example of such regression methodology. For each flow condition, temperature measurement were conducted under at least five heat flux conditions. The temperature differences were then interpolated along the channel length $X$ for each zone (defined in Figure 3) to generate a specific graphic like Figure 7 for each zone. The regressed slope of these data points were then equal to the heat transfer coefficient of this specific location.

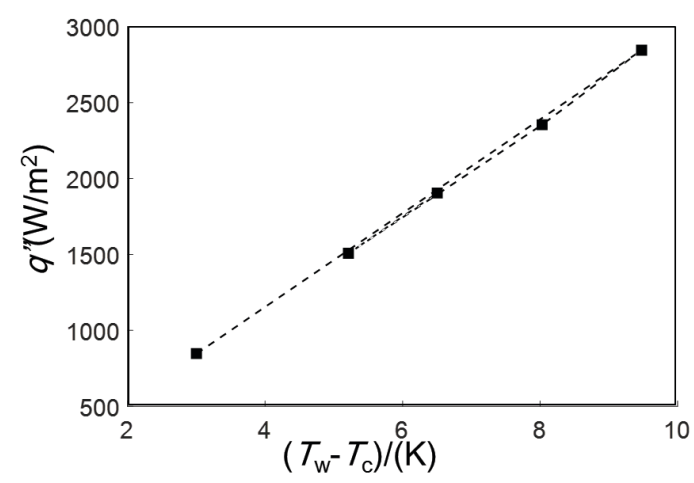

Figure 7 Regression Procedure to Calculate the Heat Transfer Coefficient 


\section{Uncertainty analysis and Validation}

As this paper used linear least square regression method to get the heat transfer values, the uncertainty of the heat transfer coefficients was dominated by the uncertainty of heat flux measurement, temperature difference measurement, and the experimental conditions. In present study, the uncertainty of bulk temperature was estimated at $0.5 \mathrm{~K}$. Uncertainty of wall temperature was estimated at $0.12 \mathrm{~K}$, including the uncertainty of the solid thermocouples $( \pm 0.1 \mathrm{~K})$ and the temperature difference caused by heat conduction through aluminium sheets (around $0.02 \mathrm{~K}$ ). Uncertainty of heat flux, counting both convective and radiation heat loss, and the deviation of the power supply output, was estimated at 5\%. Using the theory of uncertainty propagation developed by Kline and McClintock [31, 32], the total uncertainty of present heat transfer coefficients was estimated at 5.0 7.1\% depending on local geometries and work conditions. Additionally, the uncertainty of mass flow rate measurement was around $2 \%$. Uncertainty of pressure drop was 7\%. Figure 8 shows a comparison of heat transfer between present study and Florschuetz's [3] Correlation for Case 1 which had purely parallel topology. Results indicated a maximum under prediction of $20 \%$ for present measurement, which was acceptable due to the difference in measurement method and uncertainty levels. 


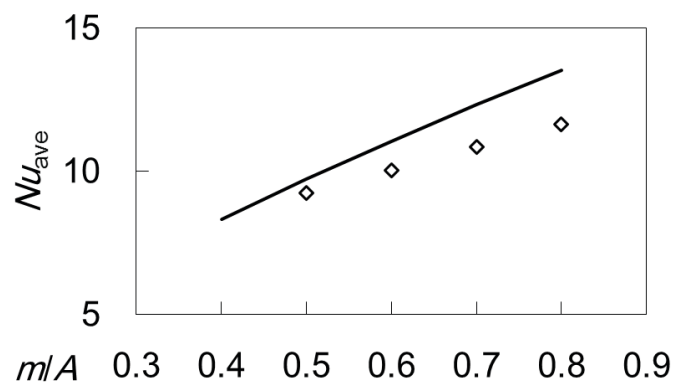

$\diamond$ Present Experiment -Florschuetz(1981)

Figure 8 Comparison between present study and Florschuetz's Correlation for Case 1

\section{Results and Discussion}

Present study seeks to reveal and model the effect of topology on heat transfer and pressure drop of hybrid linked jet impingement. Data presented in this section were broken down into local heat transfer distribution, overall averaged heat transfer and pressure drop. With the aid of the local heat transfer phenomena observed in the experiments, present study successfully derived a heat transfer correlation as a function of the topology number $(n)$, which provides quantitative description on topology effect and in turn addresses the focus of this paper.

\section{Local heat Transfer distribution}

Figure 9 shows the local Nusselt number distribution of the eight configurations, each with a unique topology as indicated in Figure 2. The plotted curves include data obtained from five groups of mass flow rates ranging from 0.4 to $0.8 \mathrm{~kg} / \mathrm{m}^{2} \mathrm{~s}$. Nusselt number presented by each of the data points represents the heat transfer level of one of the eight pieces of aluminium sheets (zones) on the target surfaces. Heat transfer typically increases with the increase in mass flow rate, while similar trends in distribution and relative magnitudes were observed for different mass flow rates. 
Heat transfer in Case 1 experiences a very high peak at the first jet, which immediately decreases by $40 \%$ and stays stable for the remaining jets. This is due to the 45 degree inclination of jets located on the vertical plates. The slight oscillation in the heat transfer from zones 2 to 7 might results from the uncertainty of the measurement method. Heat transfer in zone 8 is higher than zone 7 due to the flow extraction and boundary layer regeneration, and is also observed for other topologies. 

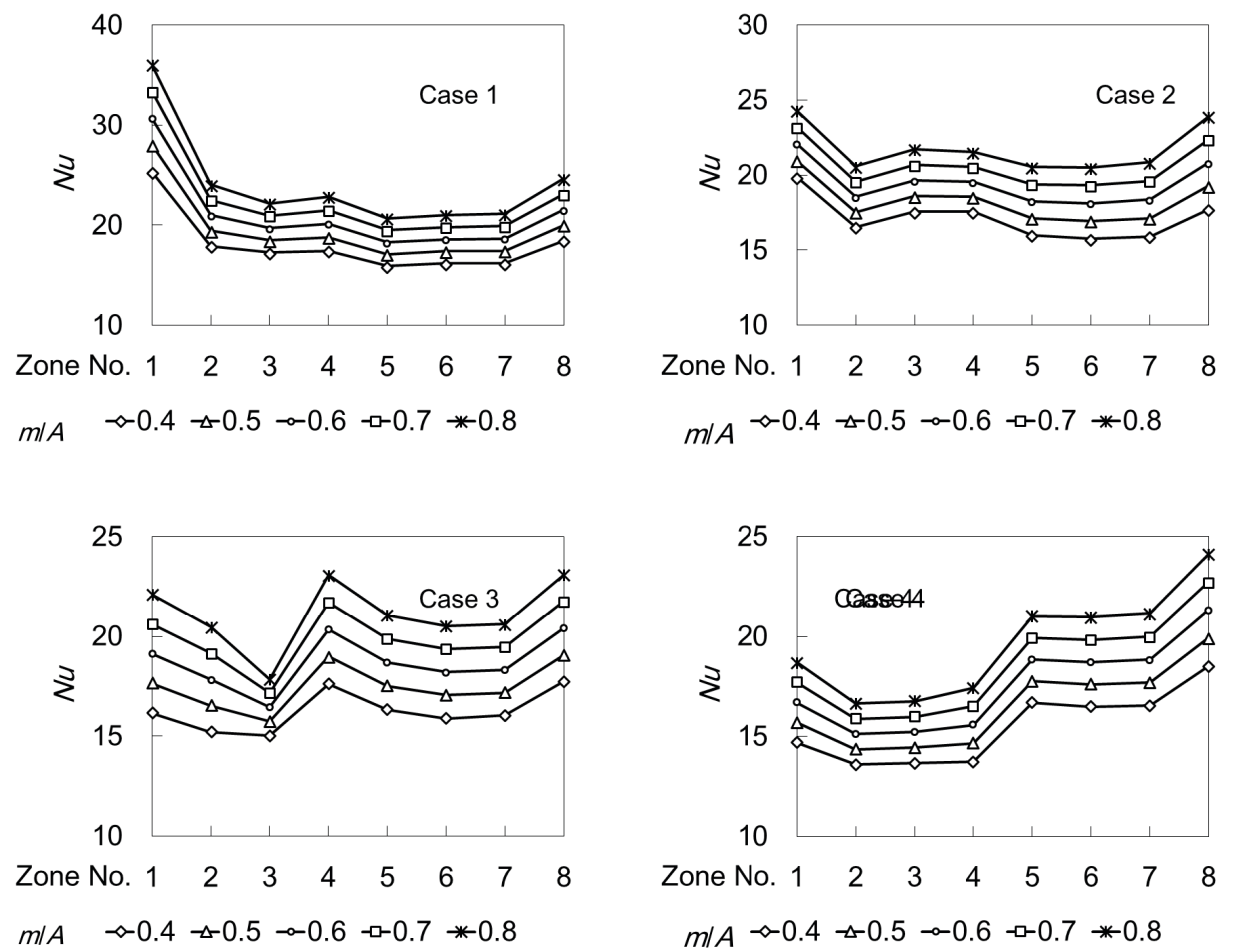

$m / A \leadsto 0.4 \rightarrow 0.5 \quad-0.6 \quad-0.7 * 0.8$
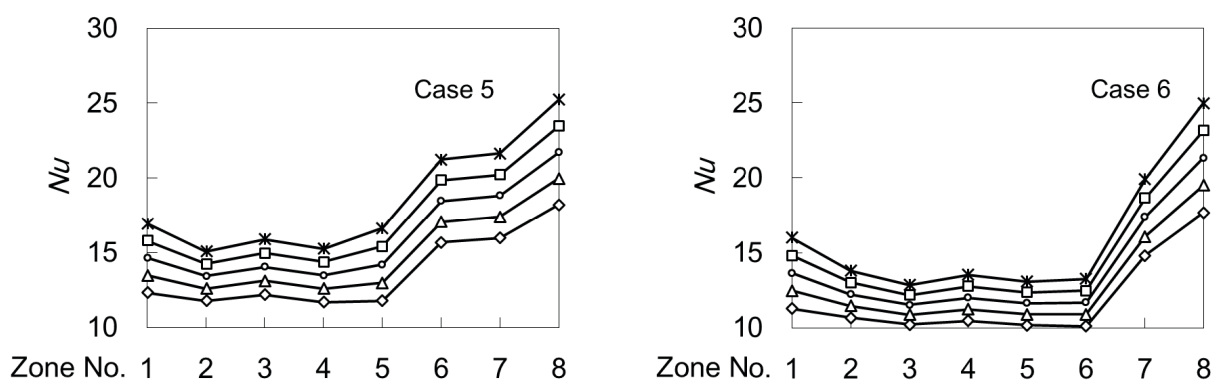
$m / A \gg 0.4 \rightarrow 0.5 \rightarrow 0.6-0-0.7 * 0.8$

$m / A \diamond 0.4 \triangleleft-0.5 \rightarrow 0.6-0-0.7 * 0.8$
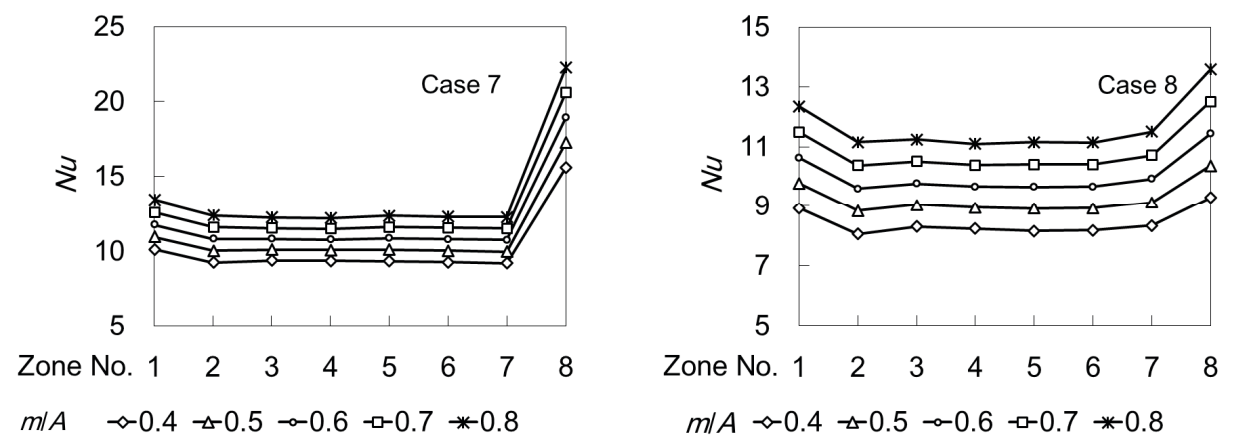

Figure 9 Heat Transfer Distribution for Hybrid Linked Jet Impingement Channels with Different Topologies 
Heat transfer in Case 2 shows similar phenomena but the heat transfer level in zone 1 gets much lower than Case 1 because of the presence of the second jet in the horizontal wall (see Figure 2), which shares the coolant amount with zone 1 and decreases the intensity of both jet flow. Furthermore, due to the effect of cross flow, heat transfer in zone 2 gets lower than zone 1 . Heat transfer in zones 3 to 8 then recovers to a similar level with that of Case 1 as a result of identical geometry and extremely similar flow condition in these regions (zones 3 to 8 ).

Similarly, for the remaining cases, the downstream regions of each topology, with geometry identical with Case 1 , all have similar heat transfer with Case 1 in those specific zones, for example zones 4 to 8 of case 3 , zones 7 and 8 for case 6 , etc. However, for the upstream parts, heat transfer just keeps decreasing with the increase in number of jets located in the horizontal plate. Again, this is due to the flow distribution among the parallel jets.

Additionally, present study provides a comparison among the eight topologies using Figure 10, where the data for $m / A=0.6 \mathrm{~kg} / \mathrm{m}^{2} \mathrm{~s}$ are plotted together. The heat transfer distribution in Figure 10 further reveals two regions with different heat transfer mechanism as mentioned above. In these hybrid linked jet impingement channels, heat transfer in the location of parallel jets are dominated by the number of jets sharing the coolant. Cross flow somehow affects heat transfer in this area. Downstream of those parallel jets, each jet is located in a separated vertical plate. Heat transfer level in these areas are almost constant as the flow conditions are consistent. Cross flow effect is eliminated in these area while potential vortex development from upstream to downstream may slightly change the heat transfer. Such apparent heat transfer features can be further quantified by analytical modelling. 


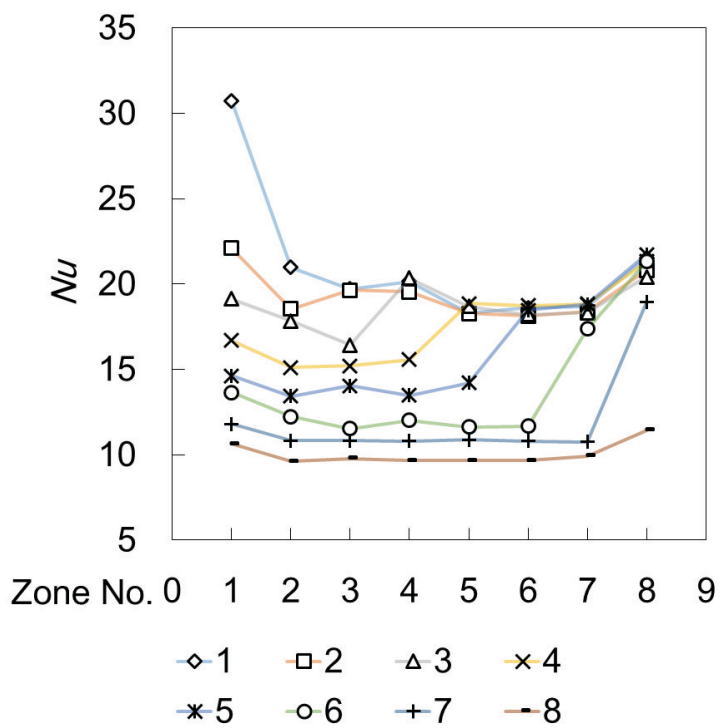

Figure 10 Comparison of Heat Transfer Distribution between Different Topologies, $\mathrm{m} /$ $A=0.6 \mathrm{~kg} / \mathrm{m}^{2} \mathrm{~s}$

\section{Overall averaged heat transfer and pressure drop}

Present paper also evaluated the overall performances of the eight proposed topologies, which include the overall averaged Nusselt number and the pressure drop. Figure 11 shows the Nusselt number averaged across zone 1 to 8 in each configuration, plotted as a function of mass flow rates. Among all the topologies, Case 1 has the highest heat transfer level due to its pure serial topology which contains maximum number of serial linked jets and makes the most use of the coolant. This phenomenon agrees well with the heat transfer distribution data mentioned above, in which the heat transfer of Case 1 is globally higher than other cases. The overall averaged Nusselt number decreases with the increase of case number because the upstream coolant gets more dispersed by more parallel jets. As compared to the traditional design Case 8 , the most significant enhancement in heat transfer caused by changing topology can be $100 \sim 150 \%$. Additional analytical analysis indicates that the Nusselt number data points 
presented in Figure 11 fit quite well with a function of $(m / A)^{0.4}$ for all the topologies, which is quite similar with correlations in literatures. Such trends of data indicate that the heat transfer is impingement dominated and can be modelled with the function of $(m / A)^{0.4}$

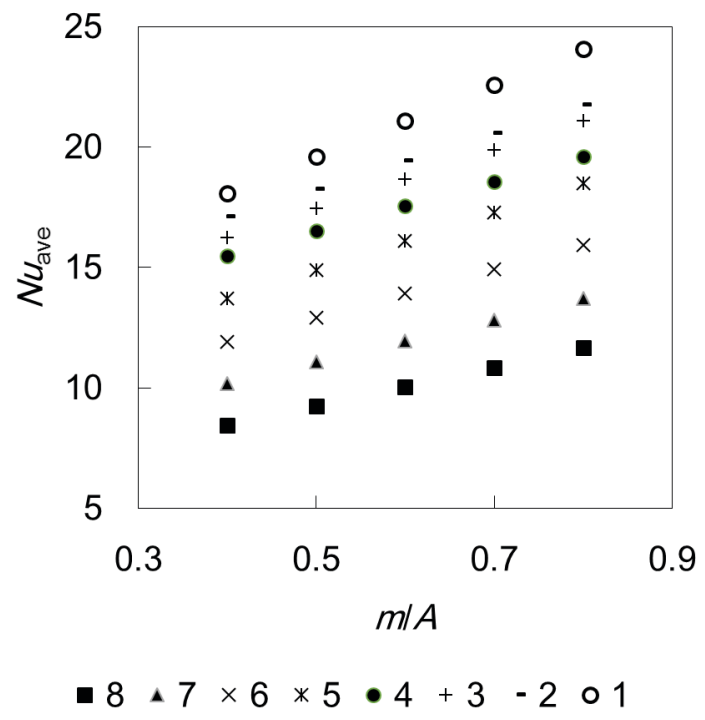

Figure 11 Overall Averaged Nusselt Number for Different Topologies

Also included in this section is the pressure drop of all the tested topologies and mass flow rates as presented by Figure 12. Exponential fitting of pressure drop with mass flow rate shows formulas of $(m / A)^{1.5 \sim 1.8}$. Such exponents of less than 2 can be explained by the high jet velocity in the serial jets, where the flow becomes compressible and the density gets higher to reduce the velocity. Pressure drop typically increases with the increase in case number. Serial linked jets cause high pressure drop due to their significant blockage of the cross section areas. Although Case 1 gets more than twice of the heat transfer of Case 8, it also spends around 20 times more of pressure drop. Such high pressure drop limits the use of serial linked jet impingement, i.e., in most cases, serial linked jets can only be used in rotor airfoils or together with 
film cooling holes, where pressure drop is not that critical. However, the traditional designs with pure parallel jets are known to be unable to make use of the pressure drop fully and have too low heat transfer, for example some zones in turbine vanes. Data obtained from present study suggest the usage of intermediate topologies, i.e. hybrid linked jets, in the location capable of higher pressure drop than traditional design. In those conditions, designers will be able to adjust the topology number $n$ (number of parallel jets) to fit the pressure drop and, in the meantime, enhance the heat transfer as much as possible.

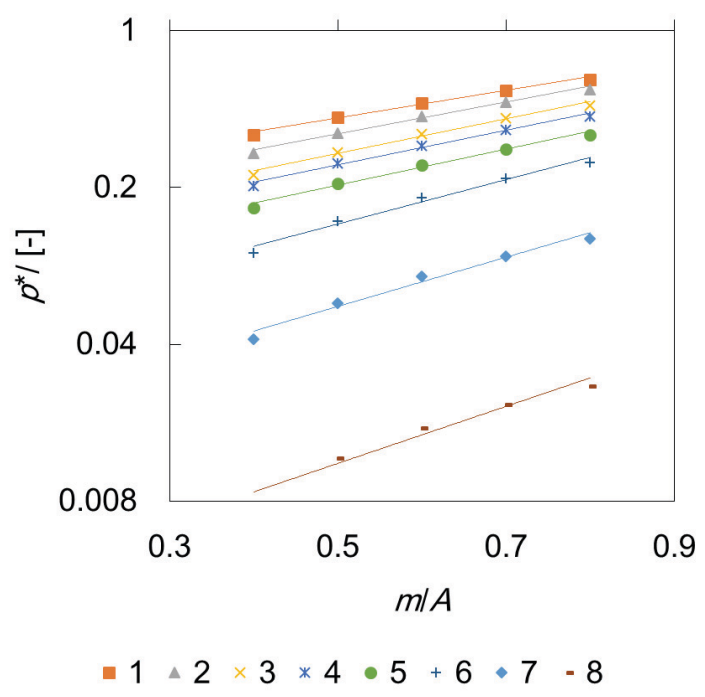

Figure 12 Non-dimensional Pressure Drop for different Topologies

\section{Heat transfer modelling on topology effect}

As no previous study has included topology as a variable of impingement experiments, present paper attempts to quantitatively model the effect of topology on heat transfer. The effort will also identify whether the complex topologies can be represented by a simple function of $n$ (i.e. whether the case number can be used as topology number). 


\section{Effect of Topology on Hybrid-linked Jet Impingement}

The correlation developed in present study only includes two variable parameters of impingement: topology (case) number $n$ and mass flow rate $m / A$. The regression and derivation process considers two aspects of the topology on heat transfer: a) heat transfer for the parallel jets depends on the local mass flow rate which is corresponding to the local mass flow rate around $(m / A) / n$, while the heat transfer for serial jets is independent of topology number $\mathrm{n}$ as they use all the coolant $m / A$; $\mathrm{b}$ ) the overall averaged Nusselt number is simply averaging of the local zone values, which results in a weighted average of $[(m / A) / n]^{0.4}$ and $(m / A)^{0.4}$. With all the above assumption, present study finally obtained a correlation formula as follows in Eq. (5)

$$
N u_{\text {ave }}=29.3(n / 8)[(m / A) / n]^{0.4}+25.5(1-n / 8)(m / A)^{0.4}
$$

Figure 13 shows the comparison between the experimental data (horizontal axis) and the correlation predicted data (vertical axis). Results indicate that the experimental data fits well with the correlation function with a maximum error less than $\pm 7 \%$, which, in turn, proves that the case number $n$ in present study can be used to represent the specific topologies of each configuration. Additionally, Figure 14 provides a curve of overall averaged Nusselt numbers plotted as a function of topology number $n$. Each experimental data point comes with an error bar representing the $\pm 7 \%$ uncertainty of the steady state measurement. Again, the correlation's predicted curve fits well with the measured data. Such analysis also provides a basic formula for future studies on topology effect for impingement cooling. Numerous work still needs to be done to complete the correlation with all the geometric parameters like $P_{\mathrm{x}}, P_{\mathrm{y}}, P_{\mathrm{z}}$, etc. 


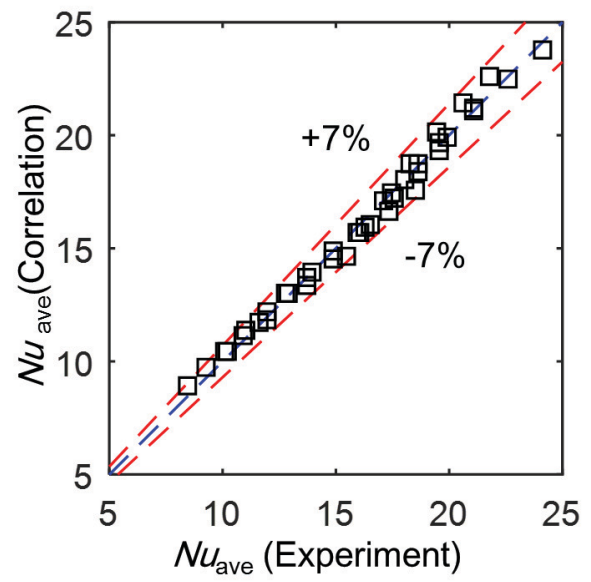

Figure 13 Comparison of Nusselt Number between experimental data and the Correlation

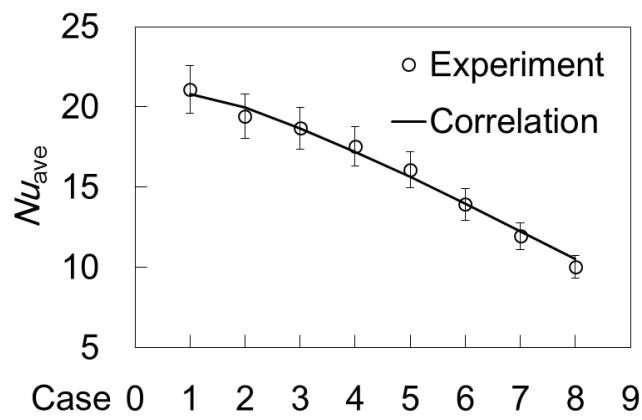

Figure 14 Comparison of Overall Averaged Nusselt Number between experimental data and the Correlation

\section{Conclusion}

Present paper considered hybrid-linked jet impingement cooling channels which involve both parallel linked jets and serial linked jets. Eight configurations with different topologies were tested under five mass flow rates ranging from 0.4 to $0.8 \mathrm{~kg}$ / $\mathrm{m}^{2} \mathrm{~s}$. The equivalent Reynolds numbers range from 12,000 to 24,000 for Case 1 . Both heat transfer data and pressure drop data were obtained from the steady state experiments, which indicated the following conclusions: 
(1)The heat transfer for the parallel jets decreases with increasing of the total number of parallel jets. Due to the parallel linkage, the mass flow rate of each jet in the horizontal plate is significantly lower than the mass flow rate in serial jets. Increasing the number of parallel jets causes decrease in jet velocities and reduces the heat transfer.

(2)The heat transfer for the serial jets stay consistent regardless of the change of topology. Mass flow rate in each serial jet equals the total mass flow rate in the associated row. Although the serial jets are inclined, the heat transfer level of serial jets are typically higher than parallel jets due to the concentration of mass flow rate.

(3)The most significant enhancement of heat transfer is found in Case 1 which has purely serial linked jets. As compared to the traditional design, Case 8, the purely serial linked jets increases the heat transfer by $100 \sim 150 \%$. However, the pressure drop of such configuration is around 20 times higher than traditional designs.

(4)Correlation modeling work in present study shows that the overall averaged heat transfer is a weighted average of $[(m / A) / n]^{0.4}$ and $(m / A)^{0.4}$, which represents the heat transfer induced by parallel jets and serial jets respectively.

The hybrid-linked jet impingement concept developed in present study has a potential to provide more flexibility to cooling channel designs. Future study may focus on the effect of geometric parameters and the total number of jets. 


\section{Effect of Topology on Hybrid-linked Jet Impingement}

\section{Acknowledgement}

This material is based upon work supported by the Department of Energy under Award Number DE-FE0025793.

This report was prepared as an account of work sponsored by an agency of the United States Government. Neither the United States Government nor any agency thereof, nor any of their employees, makes any warranty, express or implied, or assumes any legal liability or responsibility for the accuracy, completeness, or usefulness of any information, apparatus, product, or process disclosed, or represents that its use would not infringe privately owned rights. Reference herein to any specific commercial product, process, or service by trade name, trademark, manufacturer, or otherwise does not necessarily constitute or imply its endorsement, recommendation, or favoring by the United States Government or any agency thereof. The views and opinions of authors expressed herein do not necessarily state or reflect those of the United States Government or any agency thereof.

\section{Reference}

1. Han B., and Goldstein R. J., 2001, Jet-impingement heat transfer in gas turbine systems, International Symposium on Heat Transfer in Gas Turbine Systems (Turbine 2000), New York Acad Sciences, New York vol. 934 pp. 147-161..

2. Viskanta R., 1993, Heat transfer to impinging isothermal gas and flame jets, Experimental Thermal and Fluid Science, 6(2): p. 111-134.

3. Florschuetz L. W., Berry R. A., and Metzger D. E., 1981, Streamwise Flow and Heat Transfer Coefficients for Inline and Staggered Arrays of Circular Jets with Crossflow of Spent Air, ASME J. Heat Trans., Vol. 102, pp. 132-137. 
4. Zuckerman N., and Lior N., 2005, Impingement heat transfer: Correlations and numerical modeling, ASME J. Heat Trans., 127(5): pp. 544-552.

5. Han J. C., Dutta S., Ekkad S. V., 2013, Gas Turbine Heat Transfer and Cooling Technology, CRC Press, Florida, US, Chap. 5.

6. Ricklick M., and Kapat J. S., 2011, Determination of A Local Bulk Temperature Based Heat Transfer Coefficient for the Wetted Surfaces in A Single Inline Row Impingement Channel, ASME J. Turbomach., 133(3).

7. Ricklick M., Claretti R., and Kapat J. S., 2010, Channel Height and Jet Spacing Effect on Heat Transfer and Uniformity Coefficient on an Inline Row Impingement Channel, ASME Paper No. GT-2010 -23757.

8. Ricklick M., Kersten S., Krishnan V., Kapat J. S., 2009, Effects of Channel Height and Bulk Temperature Considerations on Heat Transfer Coefficient of Wetted Surfaces in A Single Inline Row Impingement Channel, ASME Paper No. HT-2008-56323

9. Taslim M. E., and Bethka D., 2009, Experimental and Numerical Impingement Heat Transfer in An Airfoil Leading-edge Cooling Channel with Cross-flow, ASME J. Turbomach., 131(1). p.011021

10. Taslim M. E., and Khanicheh A., 2006, Experimental and Numerical Study of Impingement on An Airfoil Leading Edge With and Without Showerhead and Gill Film Holes, ASME J. Turbomach., 128(2), pp. 310-320.

11. Taslim M. E., Bakhtari K., and Liu H., 2003, Experimental and Numerical Investigation of Impingement on A Rib-roughened Leading-edge Wall, ASME J. Turbomach., 125(4), pp. 682-691.

12. Parsons J. A., Han J., and Lee C.P., 2003, Rotation Effect on Jet Impingement 
Heat Transfer in Smooth Rectangular Channels with Four Heated Walls and Film Coolant Extraction, ASME Paper No. GT- 2003-38905.

13. Kreatsoulas J., Kerrebrock J., Epstein A., Rogo C., 1987, Experimental Data Correlations for The Effects of Rotation on Impingement Cooling of Turbine Blades, 23rd Joint Propulsion Conference, San Diego, California, Paper No. AIAA-87-2008.

14. Kreatsoulas J., Kerrebrock J., Epstein A., Rogo C., 1985, Effects of Rotation on Impingement Cooling of Turbine Blades, 21st Joint Propulsion Conference, Monterey, California, Paper No. AIAA-85-1217.

15. Elston C. A., and Wright L. M., 2012, Leading Edge Jet Impingement under High Rotation Numbers, ASME Paper No. IMECE-2012-88332.

16. Wright L. M., and Elston C. A., 2012, Experimental Investigation of Heat Transfer in A Leading Edge, Two-Pass Serpentine Passage at High Rotation Numbers, ASME Paper No. HT-2012-58360.

17. Hong S. K., Lee D. H., and Cho H. H., 2009, Heat/mass Transfer in Rotating Impingement/effusion Cooling with Rib Turbulators, International Journal of Heat and Mass Transfer, 52(13-14), pp. 3109-3117.

18. Hong S. K., Lee D. H., and Cho H. H., 2009, Effect of Jet Direction on Heat/ mass Transfer of Rotating Impingement Jet, Applied Thermal Engineering, 29(14-15), pp. 2914-2920.

19. Hong S. K., Lee D. H., and Cho H. H., 2008, Heat/mass Transfer Measurement on Concave Surface in Rotating Jet Impingement, Journal of Mechanical Science and Technology, 22(10), pp. 1952-1958.

20. Lamont J. A., Ekkad S. V. and Alvin M. A., 2012, Detailed Heat Transfer 
Measurements Inside Rotating Ribbed Channels Using the Transient Liquid Crystal Technique, ASME J. Thermal Sci. Eng. Appl., 4(1). p. 011002.

21. Lamont J. A., Ekkad S. V., and Alvin M. A., 2012, Effects of Rotation on Heat Transfer for A Single Row Jet Impingement Array with Crossflow, ASME J. Heat Trans., 134(8). p. 082202.

22. Lamont J. A., Ekkad S. V., and Alvin M. A., 2014, Effect of Rotation on Detailed Heat Transfer Distribution for Various Rib Geometries in Developing Channel Flow, ASME J. Heat Trans., 136(1). p. 011901.

23. Li W. H., Yang L., Li X. Y., Ren J., Jiang H.D., Ligrani P.M., Effect of Reynolds Number, Hole Patterns and Hole Inclination on Cooling Performance of an Impinging Jet Array: Part I: Convective Heat Transfer Results and Optimization, ASME Paper No. GT2016-56205.

24. Li W. H., Yang L., Li X. Y., Ren J., Jiang H.D., Ligrani P.M., Effect of Reynolds Number, Hole Patterns, Target Plate Thickness on Cooling Performance of an Impinging Jet Array, Part II: Conjugate Heat Transfer Results and Optimization, ASME Paper No. GT2016-56768.

25. Haumann J., Knopfli A., Sattelmayer T., and Tresch R., 1995, Apparatus for Impingement Cooling, US patent 5,467,815.

26. Correia H. S., 1996, Impingement Cooling Apparatus for Turbine Shrouds Having Ducts of Increasing Cross-Section Area in the Direction of PostImpingement Cooling Flow, US Patent 5480281

27. Bunker R.S., and Wallace T.T., 1994, Turbine Airfoil with Double Shell Outer Wall, US Patent 5,328,331.

28. Esposito E. I., Ekkad S. V., Kim Y., and Dutta P., 2009. Novel Jet Impingement 
Cooling Geometry for Combustor Liner Backside Cooling, Journal of Thermal Science and Engineering Applications 1:021001-8.

29. Chi Z. R., Kan R., Ren J., and Jiang H. D., 2013. Experimental and Numerical Study of the Anti-Crossflows Impingement Cooling Structure, International Journal of Heat and Mass Transfer 64:567-580.

30. Yang L., Li W. H., Ren J., Chyu M. K., Jiang H. D. "Influence of Topology on Heat Transfer in a Double Wall Cooling Channel: Potential of Series-Linked Jets,” ASME Paper No. GT2016-56270.

31. Kline, S. J., McClintock, F. A., 1953, "Describing uncertainties in single sample experiments," Mechanical Engineering, 75, pp. 3-8.

32. Moffat, R. J., 1988, "Describing the uncertainties in experimental results," Experimental Thermal and Fluid Science, 1(1), pp. 3-17. 


\section{Figure Captions}

Figure 1 Concept of Hybrid Linked Jet Impingement Channel

Figure 2 Definition of Topologies for Each Case

Figure 3 Definition of Geometric Parameters

Figure 4 Steady State Heat Transfer Test Rig for Impingement Cooling

Figure 5 Cross Section View of Test Section Design

Figure 6 Top View of the Assembled Test Section

Figure 7 Regression Procedure to Calculate the Heat Transfer Coefficient

Figure 8 Comparison between present study and Florschuetz's Correlation for Case 1

Figure 9 Heat Transfer Distribution for Hybrid Linked Jet Impingement Channels with Different Topologies

Figure 10 Comparison of Heat Transfer Distribution between Different Topologies, $\mathrm{m} /$ $A=0.6 \mathrm{~kg} / \mathrm{m}^{2} \mathrm{~s}$

Figure 11 Overall Averaged Nusselt Number for Different Topologies

Figure 12 Non-dimensional Pressure Drop for different Topologies

Figure 13 Comparison of Nusselt Number between experimental data and the

Correlation

Figure 14 Comparison of Overall Averaged Nusselt Number between experimental data and the Correlation 